This accepted version of an article published by online by Elsevier on 25 April 2017 in Agricultural Systems. Published version available from: https://doi.org/10.1016/j.agsy.2017.04.006

Accepted version made available under CC-BY-NC-ND 4.0 International License from SOAS Research Online:

http://eprints.soas.ac.uk/24041/

1

2

\title{
Maintaining Rice Production while Mitigating Methane and Nitrous Oxide Emissions from Paddy Fields in China: Evaluating Tradeoffs by Using Coupled Agricultural Systems Models
}

Zhan Tian ${ }^{1}$, Yilong Niu ${ }^{1,2}$, Dongli Fan², Laixiang Sun ${ }^{3,4,5}$, Gunther Ficsher ${ }^{4}$, Honglin Zhong ${ }^{3}$, Jia Deng ${ }^{6}$, Francesco N. Tubiello ${ }^{7}$

1. Shanghai Climate Center, Shanghai Key Laboratory of Meteorology and Health, Shanghai Meteorological Service, Shanghai 200030, China

2. Shanghai Institute of Technology, Shanghai, 201418

3. Department of Geographical Sciences, University of Maryland, College Park, MD 20742, USA

4. International Institute for Applied Systems Analysis (IIASA), A-2361 Laxenburg, Austria

5. School of Finance \& Management, SOAS, University of London, London WC1H 0XG, UK

6. Earth Systems Research Center, Institute for the Study of Earth, Oceans, and Space, University of New Hampshire Durham, NH 03824, USA

7. Statistics Division, Food and Agriculture Organization of the United Nations (FAO), Rome, Italy

Correspondence to: Dongli FAN, E-mail: fandl@sit.edu.cn; or Laixiang Sun, Email:

LSun123@umd.edu, Tel: +1-301-405-8131, Fax: +1-301-314-9299.

\section{Acknowledgement:}

This work was supported by the National Natural Science Foundation of China (Grant Nos. 41601049, 41371110, and 41671113) and the National Key Research and Development Program of China (Grant No. 2016YFC0502702). 
China is the largest rice producing and consuming country in the world, accounting for more than $25 \%$ of global production and consumption. Rice cultivation is also one of the main sources of anthropogenic methane $\left(\mathrm{CH}_{4}\right)$ and nitrous oxide $\left(\mathrm{N}_{2} \mathrm{O}\right)$ emissions. The challenge of maintaining food security while reducing greenhouse gas emissions is an important tradeoff issue for both scientists and policy makers. A systematical evaluation of tradeoffs requires attention across spatial scales and over time in order to characterize the complex interactions across agricultural systems components. We couple three well-known models that capture different key agricultural processes in order to improve the tradeoff analysis. These models are the DNDC biogeochemical model of soil denitrification-decomposition processes, the DSSAT crop growth and development model for decision support and agrotechnology analysis, and the regional AEZ crop productivity assessment tool based on agroecological analysis. The calibration of eco-physiological parameters and model evaluation used the phenology and management records of 1981-2010 at nine agro-meteorological stations spanning the major rice producing regions of China. The eco-physiological parameters were calibrated with the GLUE optimization algorithms of DSSAT and then converted to the counterparts of DNDC. The upscaling of DNDC was carried out within each cropping zone as classified by AEZ. The emissions of $\mathrm{CH}_{4}$ and $\mathrm{N}_{2} \mathrm{O}$ associated with rice production under different management scenarios were simulated with the DNDC at each site and also each $10 \times 10 \mathrm{~km}$ grid-cell across each cropping zone. Our results indicate that it is feasible to maintain rice yields while reducing $\mathrm{CH}_{4}$ and $\mathrm{N}_{2} \mathrm{O}$ emissions through careful management changes. Our simulations indicated that a reduction of fertilizer applications by $5-35 \%$ and the introduction of midseason drainage across the nine study sites resulted in reduced $\mathrm{CH}_{4}$ emission by $17-40 \%$ and $\mathrm{N}_{2} \mathrm{O}$ emission by $12-60 \%$, without negative consequences on rice yield.

KEY WORDS: Climate change; agricultural $\mathrm{CH}_{4}$ and $\mathrm{N}_{2} \mathrm{O}$ emissions; rice yield; model coupling; mitigation tradeoffs; China 


\section{INTRODUCTION}

Climate change characterized by global warming has already had observable impact on the ecological system and human society (Alley et al., 2003). The historical records show that from 1901 to 2012, the global mean surface temperature increased by $0.89^{\circ} \mathrm{C}$. This warming trend is expected to continue in the forthcoming decades and would impose even more significant impact on ecosystem and human society (IPCC, 2013). The main cause of current global warming is the anthropogenic emission of greenhouse gases (GHGs), which has led to their increased concentration in the atmosphere. Modern intensive farming, which heavily depends on chemical fertilizer application and irrigation, is the single largest source of methane $\left(\mathrm{CH}_{4}\right)$ and nitrous oxide $\left(\mathrm{N}_{2} \mathrm{O}\right)$ emissions (IPCC, 2014; FAO, 2016). Meanwhile, a warmer climate accompanied by modified water regimes exerts impact on farming practices and consequently on crop productivity (Verburg et al., 2000; IPCC, 2014). Since the global warming potential of $\mathrm{CH}_{4}$ and $\mathrm{N}_{2} \mathrm{O}$ is 25 and 298 times higher than $\mathrm{CO}_{2}$, respectively (IPCC, 2013), it is well recognized that a focus on reducing $\mathrm{CH}_{4}$ or $\mathrm{N}_{2} \mathrm{O}$ emissions may be an effective climate change mitigation strategy.

Our ability to pick these "low-hanging fruits" may however be constrained by the existence of multiple, conflicting objectives. Rice paddy cultivation in China represents a significant example to this end. On the one hand, China is the major producer and consumer of rice in the world and maintaining self-sufficiency in rice is extremely important for the country (FAOSTAT 2016). On the other, China's rice production generates significant environmental pressure, as it depends on large-scale basin irrigation and large amounts of fertilizers applications (Miao et al., 2011). Such practices have resulted in significant emissions of $\mathrm{CH}_{4}$ and $\mathrm{N}_{2} \mathrm{O}$ to the atmosphere, as well as damages to soil and water systems. Using IPCC guidelines for GHG inventories (IPCC, 2006), the emissions of $\mathrm{CH}_{4}$ from Chinese paddy fields were estimated at $7.41 \mathrm{Tg}\left(1 \mathrm{Tg}=10^{12} \mathrm{~g}\right) \mathrm{CH}_{4}-\mathrm{C}$ in 2000 , which is well over $150 \mathrm{Tg} \mathrm{CO}_{2} \mathrm{eq}$, accounting for about $29 \%$ of world total $\mathrm{CH}_{4}$ emission from rice in that year (Yan et al., 2009). These emissions levels were maintained throughout the last decade (FAOSTAT, 2016). At the same time, $\mathrm{N}_{2} \mathrm{O}$ emissions from Chinese paddy fields were estimated at $0.036 \mathrm{Tg} \mathrm{N}_{2} \mathrm{O}-\mathrm{N}$ in 2007 (Gao et al. 2011), corresponding to roughly 30\% of the total $\mathrm{N}_{2} \mathrm{O}-\mathrm{N}$ emissions from Chinese agriculture (FAOSTAT, 2016).

In the rice cultivation system, rice grain and greenhouse gas are joint products from paddy fields cultivation and there is a complex relationship between rice growing and GHG emissions. For example, $\mathrm{CH}_{4}$ production is influenced by substrate concentrations, which are 
influenced by plant root activities. Plant growth dynamic also influences soil mineral $\mathrm{N}$ through crop $\mathrm{N}$ uptake, therefore indirectly affecting $\mathrm{N}_{2} \mathrm{O}$ emission. This complexity has attracted significant research attention and various GHG mitigation measures have been tested using field experiments at paddy sites. For example, Dong et al. (2011) highlighted the tradeoff relationship between $\mathrm{CH}_{4}$ and $\mathrm{N}_{2} \mathrm{O}$ emissions, finding that an increasing application of nitrogen fertilizer will mitigate $\mathrm{CH}_{4}$ emission with reference to no fertilization, but increase $\mathrm{N}_{2} \mathrm{O}$ emissions at the same time. Itoh et al. (2011) found that employing midseason drainage as a water management technique in rice fields reduced the combined climate forcing of $\mathrm{CH}_{4}$ and $\mathrm{N}_{2} \mathrm{O}$ in comparison with basin irrigation. Based on experimental evidence, Johnson-Beebout et al. (2009) concluded that simultaneous minimization of both $\mathrm{CH}_{4}$ and $\mathrm{N}_{2} \mathrm{O}$ emission could not be maintained in rice soils, but that appropriate water and residue management could nonetheless reduce greenhouse gas emissions. Wu et al. (2008) showed that employing conservation tillage methods, especially no-tillage, mitigated GHG emission from rice fields by about $15 \%$. However, it is difficult to extrapolate these field-based results to large regional scales, because of high inherent variability over space and time. Such variability may instead be addressed by agricultural systems models that, while capturing the fundamental soil crop atmosphere dynamics highlighted by field experiments, can be used to further estimate the regional variability of associated emissions as a function of the wide range of soil, water and climatic parameters that exists over large scales (Jones et al., 2016).

The DeNitrification-DeComposition (DNDC) model is one of the most widely accepted biogeochemistry process-based models in the world (Wang and Chen, 2012; Gilhespy et al., 2014). The model has been evaluated against observations worldwide (e.g., Beheydt et al., 2007; Giltrap et al., 2010; Gilhespy et al., 2014). The development of a GIS coupled to highresolution soil maps in recent versions of this model, allows DNDC to also estimate GHG emissions at regional and national levels, in support of national inventories and including the impacts of rice rotations (e.g., Gilhespy et al., 2014; Zhang et al. 2016; Li et al. 2005; Chen et al. 2016).

With the GIS application, an array of weather and soil data could be employed to support DNDC model-based regional simulations. However, two limitations currently undermine such simulations. First, the phenological and physiological parameters as the key input of DNDC are typically calibrated with the subjective optimization method (McCuen, 2003), meaning that parameter values are manually adjusted based on the modeler's subjective knowledge of the parameter, model, and data (Wang and Chen, 2012). A consequence of this limitation is that the default cultivar parameter values in DNDC 
characterize only one rice cultivar for all of China, thus failing to represent the richness and regional diversity of cultivars that exists in this country. Second, as highlighted in Zhang et al. (2016), most DNDC studies were conducted at the county level in the case of China or at large spatial simulation units, with a resolution about $0.5^{\circ} \times 0.5^{\circ}$ (e.g., $\mathrm{Li}, 2000$; Pathak et al., 2005; Tang et al., 2006; Gao et al., 2014). This coarseness does not allow to properly capture the impacts of soil heterogeneity and the associated management measures within a county or a large spatial unit, resulting in poor spatial performance of the simulation models.

To overcome the above weaknesses of DNDC and to more accurately evaluate the tradeoffs between maintaining the current level of rice production and reducing GHG emissions from farming activities, we coupled three state-of-the-art agricultural systems models in order to capitalize on their individual comparative advantages. They are the biogeochemistry process-focused DNDC model, the crop growing process-focused model Decision Support System for Agro-technology Transfer (DSSAT) (Jones et al. 2003), and the Agro-Ecological Zone (AEZ) model (Fischer et al. 2012), a widely used regional crop productivity assessment tool. The two crop simulation models (DSSAT and AEZ) are designed to assess the impacts of multiple climate factors on crop growth and grain yield. They are widely employed in climate impact studies (Challinor et al., 2014; Thorp et al., 2008; Seidl et al., 2001). We investigated how such coupling can improve the spatial performance of DNDC for the case of paddy rice production in China. Our parameters calibration and model evaluation used the observed phenology and management records at nine representative agro-meteorological stations, spanning the major rice producing regions of China. We first calibrated eco-physiological (cultivar) parameters for rice growth using the Generalized Likelihood Uncertainty Estimation (GLUE) algorithm provided by DSSAT, which uses Monte Carlo sampling from prior distributions of the coefficients and a Gaussian likelihood function to determine the best cultivar coefficients, based on the observation data. We then followed a procedure as presented in Section 2.4.2 to convert these ecophysiological cultivar parameters into DNDC required parameters. In this way, we enriched the value set of cultivar parameters of the DNDC model, which is essential for meaningfully upscaling, via the assistance of AEZ, the DNDC runs to the rice cropping zones of China. With such coupling between the three models, we evaluated rice yield levels and the corresponding $\mathrm{CH}_{4}$ and $\mathrm{N}_{2} \mathrm{O}$ emissions under different management scenarios, at a resolution of $10 \times 10 \mathrm{~km}$, seeking to highlight those water and fertilizer management solutions that could lead to significant reduction of $\mathrm{CH}_{4}$ and $\mathrm{N}_{2} \mathrm{O}$ emissions without causing reductions in rice 
production.

\section{MATERIALS AND METHODS}

\subsection{The study sites}

We selected nine agro-meteorological observation stations based on the following criteria from the original hardcopy records filed in the Data Center of China Meteorological Administration: (1) each station represents a typical cropping system for rice cultivation in China; (2) they differ in terms of geographic and climatologic characteristics; (3) each station has complete records of crop phenology for more than 20 years over the period of 1981-2010; and (4) each station has complete records of crop management for more than 5 years over the period of 1981-2010. These records include the ID, name and location (latitude and longitude) of each station; date of each major phenological stages (sowing, flowering, maturity, etc.); yield and yield components (grain weight, grain number per tiller, tiller number per plant, etc.); date, type and quantity of fertilizer application; and irrigation methods and dates. These crop phenology and management data are critical for simulating crop growing and quantifying $\mathrm{CH}_{4}$ and $\mathrm{N}_{2} \mathrm{O}$ emission from crop fields. Table 1 and Figure 1 report names, locations, and geographical features of these nine stations.

(Table 1 and Figure 1 are about here)

\subsection{Input Datasets at the Grid-cell Level}

Observed daily weather data, including minimum and maximum air temperature, daily sunshine hours, precipitation, relative humidity, and wind speed, for 1981-2010 at over 700 observation stations nationwide were provided by the Data Center of China Meteorological Administration. Because all three models need solar radiation data, we employed the empirical global radiation model to calculate daily radiation levels (Pohlert, 2004). These point-based data are imported to ArcGIS together with the coordinates and then interpolated into $10 \mathrm{~km}$ spatial resolution raster data.

The Harmonized World Soil Database (HWSD, cf. FAO/IIASA/ISRIC/ISSCAS/JRC, 2009) provides reliable and harmonized soil information at the grid cell level for the world, with a spatial resolution of $1 \mathrm{~km} \times 1 \mathrm{~km}$ for China. The soil is divided into topsoil $(0-30 \mathrm{~cm})$ and subsoil (30-100 cm). Each grid cell in the database is linked to commonly used soil parameters. Most of the minimum soil properties required by the DSSAT and DNDC models can be extracted directly from the HWSD soil database. For the missing soil surface albedo, 
we used the soil color from the World Inventory of Soil Emission Potentials (WISE) soil database (Batjes, 2009) and determined the soil surface albedo with the standard given by Ritchie et al. (1989). We calculated other missing soil properties with extracted soil properties and procedures provided in the DSSAT literature (Gijsman et al., 2002, 2007), such as USDA curve number (Lane, 1982) and drainage rate, root growth factor, upper and lower limit of plant extractable soil water.

The map of paddy fields is extracted from the National Land Cover database (100 $\mathrm{m} \times$ $100 \mathrm{~m}$ ) provided by the Institute of Geographical Sciences and Natural Resource Research (IGSNRR) of the Chinese Academy of Sciences. The reference year for the map is 2000. This land cover database is produced from visual interpretation of Landsat ETM/ETM+ satellite images and grouped into ten categories. Paddy field is one of the major categories (Liu et al., 2005).

\subsection{Agricultural Systems Models}

\subsubsection{The DNDC model}

The DeNitrification-DeComposition (DNDC) model simulates soil carbon (C) and nitrogen $(\mathrm{N})$ biogeochemical processes in crop growth cycle. It was originally developed for simulating $\mathrm{C}$ sequestration and emissions of greenhouse gases from agricultural soils in the USA (Li et al., 1992; Li et al., 1994). During the last 25 years, the DNDC model has been developed to simulate $\mathrm{C}$ and $\mathrm{N}$ transformations in different ecosystems, such as forest, wetlands, pasture, and livestock farms. It has incorporated a relatively complete suite of biophysical and biogeochemical processes, which enables it to compute the complex transport and transformations of $\mathrm{C}$ and $\mathrm{N}$ in terrestrial ecosystems under both aerobic and anaerobic conditions (Gilhespy et al., 2014; Li 2007).

DNDC is comprised of six interacting sub-models: soil climate, plant growth, decomposition, nitrification, denitrification, and fermentation. The soil climate, plant growth, and decomposition sub-models convert the primary drivers into soil environmental factors. The nitrification, denitrification, and fermentation sub-models simulate $\mathrm{C}$ and $\mathrm{N}$ transformations that are mediated by soil microbes and controlled by soil environmental factors (Li 2000; Li et al., 2012). In DNDC, crop biomass and yield are simulated at daily time steps by considering the effects of several environmental factors on plant growth, including radiation, air temperature, soil moisture, and $\mathrm{N}$ availability. Methane flux is predicted by modeling $\mathrm{CH}_{4}$ production, oxidation, and transport processes. $\mathrm{CH}_{4}$ production is simulated by calculating substrate concentrations (i.e., electron donors and acceptors) 
resulting from decomposition of SOC (soil organic carbon) as well as plant root activities including exudation and respiration, and then by simulating a series of reductive reactions between electron donors (i.e., $\mathrm{H}_{2}$ and dissolved organic carbon) and acceptors (i.e., $\mathrm{NO}_{3}^{-}$, $\mathrm{Mn}^{4+}, \mathrm{Fe}^{3+}, \mathrm{SO}_{4}{ }^{2-}$, and $\mathrm{CO}_{2}$ ). Redox potential, temperature, $\mathrm{pH}$, along with the concentrations of electron donors and acceptors are the major factors controlling the rates of $\mathrm{CH}_{4}$ production and oxidation. DNDC simulates $\mathrm{CH}_{4}$ transport via three pathways, including plant-mediated transport, ebullition, and diffusion (Fumoto et al., 2008; Zhang et al., 2002). $\mathrm{N}_{2} \mathrm{O}$ is simulated as a by-product of nitrification and denitrification. As microbial-mediated processes, both nitrification and denitrification are subject to complex regulation of numerous environmental factors, such as concentrations of mineral $\mathrm{N}$, availability of dissolvable organic carbon (DOC), redox potential, and temperature in DNDC (Li, 2000). Farming management practices, such as synthetic fertilizer application, manure use and irrigation, have been parameterized to regulate the soil $\mathrm{N}$ dynamics, DOC availability, and/or soil environments, and therefore regulate $\mathrm{N}_{2} \mathrm{O}$ emissions from soils. In this research, we use the latest version of DNDC (DNDC 95).

\subsubsection{The DSSAT model}

The Decision Support System for Agro-technology Transfer (DSSAT) model (Jones et al., 2003; Hoogenboom et al. 2010) is a popularly-employed model for simulating crop growing dynamics (Challinor et al., 2014). The core of the DSSAT system consists of 17 crop simulation models. This research employs the Crop Environment Resource Synthesis (CERES) model, which simulates cereal crops such as wheat, rice and maize. The CERES model calculates daily phenological development (i.e., vegetative growth, flowering, grain growth, maturity and senescence phases) and biomass production in response to environmental (soil and climate) and management (crop variety, planting conditions, $\mathrm{N}$ fertilization, and irrigation) factors.

The crop cultivar parameters, which are named genetic coefficients in DSSAT, quantitatively describe how a particular genotype of a cultivar responds to environmental factors (Penning de Vries et al., 1992), thus enabling the integration of genetic information on physiological traits into crop growth models. Each crop in the model has a specific set of parameters, values of which characterizes the genetic information of different cultivars. In the CERES-rice model, 8 parameters are essential for describing the genetic information of different rice cultivars (Prasada Rao, 2008, Table 14.1). Because each station belongs to a specific cropping zone/cropping system for rice cultivation in China as we presented in 
Section 2.1, we have nine cultivars, each at one station. We employ the DSSAT-provided Generalized Likelihood Uncertainty Estimation (GLUE) method (He et al., 2010) to estimate the parameter values of the given cultivar. GLUE is a Bayesian estimation method. GLUE uses Monte Carlo sampling from prior distributions of the coefficients and a Gaussian likelihood function to determine the best coefficients based on the observation data. It has been widely used in crop and hydrological modeling (Blasone et al. 2008; He et al., 2010; Wang et al. 2015). The technical details of the GLUE estimation and a part of the estimation results were published in Tian et al. (2014). The procedure on translating DSSAT's genetic coefficients into the format of DNDC's cultivar parameters will be presented in sub-section 2.4.2.

\subsubsection{The AEZ model}

In contrast to the process-based crop growth model like DSSAT, the Agro-Ecological Zone (AEZ) model, which was jointly developed by the International Institute for Applied Systems Analysis (IIASA) and the Food and Agricultural Organization (FAO) of the United Nations, is a regional scale model to simulate land resource and crop production potential (Fischer et al., 2012). AEZ provides a standardized crop-modeling and environmental matching procedure, which classify a region into cropping zones based on climate, soil, and terrain characteristics relevant to specific crop production, and identify crop-specific limitations of prevailing agro-ecological resources under assumed levels of inputs and management conditions. This procedure in AEZ makes it well suited for crop suitability, zoning, and productivity assessments at regional, national and global scales (cf., among others, FAO, 2007; Fischer et al., 2005; Gohari et al., 2013; Masutomi et al., 2009; Tian et al., 2012, 2014; Tubiello and Fischer, 2007). In each rice-cropping zone identified by the AEZ, we have one representative observation station (Fig. 1). We assume that the rice cultivar parameters we have calibrated at the representative station are applicable for DNDC simulations across grid cells within this rice cropping zone.

\subsection{Implementation Procedure of Model Coupling}

The flowchart for effectively linking DSSAT, AEZ, and DNDC models are presented in Fig. 2. As shown in Fig.2, the central purpose of the model coupling is for finding feasible ways to reconcile the two policy goals of maintaining rice production and mitigating methane $\left(\mathrm{CH}_{4}\right)$ and nitrous oxide $\left(\mathrm{N}_{2} \mathrm{O}\right)$ emissions from paddy fields in China. The reconciliation would become more convincing if both rice production and the corresponding $\mathrm{CH}_{4}$ and $\mathrm{N}_{2} \mathrm{O}$ 
emissions are outputs of one model, and the most suitable model for this purpose is the DNDC. However, despite that DNDC model has the designed comparative advantage in simulating biogeochemistry process during crop growing cycle and it is also capable of simulating crop growing process, its simulations are subject to the condition that the representative phenological and physiological parameters related to crop growth simulations with DNDC are available as the key input information (User's Guide for the DNDC Model, http://www.dndc.sr.unh.edu/model/GuideDNDC95.pdf). To produce such representative phenological and physiological input parameters for DNDC, DSSAT has clear comparative advantage because the DSSAT model is designed for simulating very detailed crop-growing process, including phenological details. The central steps for enriching the parameter value set of rice cultivars in the DNDC model and to enable the smooth up-scaling runs of DNDC within each rice-cropping zone of China's rice growing region are as follows. (1) calibrating rice genetic coefficients at the nine agro-meteorological stations using the DSSAT model and its GLUE algorithms; (2) converting the newly calibrated genetic coefficients into the format of DNDC; (3) reclassifying the cropping zones based on the spatial relationship between observed cropping practices at the nine stations and the two-digit classification of the AEZ cropping zones, so that each rice cropping zone has only one set of DNDC parameter values; and (4) simulating $\mathrm{CH}_{4}$ and $\mathrm{N}_{2} \mathrm{O}$ emissions under different scenarios using the DNDC model with the calibrated values of crop cultivar parameters remaining stable in each of the reclassified cropping zones, under the historical climate conditions from 1981 to 2010.

(Figure 2 and Table 2 about here)

\subsubsection{Scenarios configuration}

In order to find one or more feasible management methods which can meet the dual goal of maintaining the current level of rice production and reducing GHG emissions from the current emission level, we set up 4 management scenarios and simulate rice growing and GHG emission processes for a single rice growing season under each scenario.

The first one is the "Traditional Management" (TM) scenario, in which the application of chemical fertilization follows the existing practice and irrigation follows the current continuous flooding, with the timing and intensity as recoded in the observation data of the nine study sites.

Excessive application of nitrogenous fertilizer has been widely recognized as an important source of excessive $\mathrm{N}_{2} \mathrm{O}$ emission from rice paddy fields, as discussed in the 
introduction. We define a threshold/balanced fertilizer amount which guarantees the best attainable yield with the minimum amount of necessary fertilizer application, meaning that an application amount smaller than this threshold will lead to yield reduction even under ideal weather and water management conditions, and an application amount larger than this threshold will not lead to an increase in yield. In order to find this threshold, the maximum amount of the observed fertilizer application at each station was employed as the starting point. Then we ran DNDC simulations stepwise and at each step we cut down this maximum amount by $5 \%$ and check its impact on the best attainable yield. In this way we found the ratio of the threshold/balanced fertilizer amount to the real maximum application amount at each of the 9 stations. We call this ratio the 'balanced fertilizer ratio' (Table 2). Consistent with the acknowledgement in the literature, excessive application is present in all nine stations, being 5-35\% higher than the requirement for supporting the best attainable yield. While the SCCD and JXNC sites reported a moderate extent of excessive fertilizer application, all other sites showed significant room for reducing fertilizer application amount. The above search procedure leads to the establishment of the second scenario, which consists of the balanced fertilizer application and continuous flooding irrigation method. We call it the “Balanced Fertilizer” (BF) scenario.

With the development of new crop management and cultivar breeding technology, increasing number of farmers are using the midseason field drying method to replace the traditional basin irrigation method, which could mitigate $\mathrm{CH}_{4}$ emission effectively. We name this scenario "Midseason Drainage" (MD), in which the application of fertilizer is as the observed, but irrigation management takes the midseason field drying method.

The forth scenario, we call it "Comprehensive Mitigation” (CM), combines the balanced fertilizer application and the midseason field drying irrigation method. Because changes in water management method will affect nitrification and denitrification processes, under the MD and CM scenarios, the balanced fertilizer application amount at JXNC decreases from 90\% to $80 \%$ and at LNTT increases from $80 \%$ to $95 \%$ (Table 2, BFR-1 and BFR-2).

\subsubsection{Calibration of cultivar parameters and DNDC validation}

Key rice cultivar parameters related to the simulation of crop growth and GHG emissions in DNDC include maximum biomass and C:N ratio of grain, leaf, stem and root, respectively; optimum rice growing temperature; and the required accumulative degree days (TDD) from sowing to maturity. In order to improve the information on rice cultivars in the DNDC model, we first calculate the maximum grain biomass based on the yield records at 
each observation site. We determine the best attainable yield based on the maximum value of the multi-year yield components records, which includes the maximum grain number per tiller and the corresponding grain weight, maximum tiller number per plant and the optimum plant density. This way of determining the maximum grain biomass is in line with the corresponding requirements in the DNDC setting. It also guarantees that the ways we find for reducing $\mathrm{CH}_{4}$ and $\mathrm{N}_{2} \mathrm{O}$ emission are able to maintain the best attainable yield. Second, we employ the GLUE module in the DSSAT model to calibrate the rice genetic coefficients by targeting at the maximum grain biomass at each station. We used the outputs of DSSAT model calibrated to calculate, for each site, the maximum biomass and the C:N ratio for each part of the rice plant, and also the harvest index (HI). In the calculation of the C:N ratio, we also take reference from the relevant information in the AEZ database to justify the range of our calculations. Third, optimum temperature for rice growing is translated from reference temperature in AEZ directly and the TDD is calculated based on the daily weather data during each rice growing season over the period of 1981-2010. Table 3 reports the results of the above calibration.

\section{(Tables 3-5 about here)}

We then ran the DNDC model using the newly calibrated cultivar parameter values (Table 3), and validated the model by comparing the simulations against the observed best attainable yield at the site level. The ideal field management practices are used to ensure that the growing process is free from water and nitrogen stress, and only influenced by weather and soil. We report both the ranges of simulated yields and the Relative Absolute Error (RAE), as presented in Eq. (1), to evaluate the consistency between the observed and the simulated values.

$$
\mathrm{RAE}=\frac{|\mathrm{Obs}-\mathrm{Simu}|}{\mathrm{Obs}} \times 100 \%,
$$

where "obs" refers to the observed value and "simu" the result of DNDC model simulation at the give site. Because the focus of DNDC is on the interactions between the $\mathrm{C}$ and $\mathrm{N}$ biogeochemical cycles and the primary ecological drivers in the cropping process, rather than on simulating the detailed crop growing process, the major phenology information such as plating and maturity days are the input of DNDC. This means that the performance evaluation of DNDC should be based on the comparison between observed and simulated yield and emissions. 
Table 4 reports the observed best attainable yield, the minimum, mean, and maximum of the simulated yields, and the average RAE at the nine stations for the period of 1981-2010. It shows that while at 6 of the 9 stations, the observed attainable yield lies within the uncertainty range of the simulated yields, the observed yield at JLYJ is $119 \mathrm{~kg}$ higher (with an average RAE at 4.69\%) than the simulated maximum and that at SDLY and GDGZ is $313 \mathrm{~kg}$ (average RAE 7.72\%) and $290 \mathrm{~kg}$ (average RAE 8.13\%) lower than the simulated minimum, respectively. Given that the gap between the observed yield and the nearest border value of the simulated yield is less than $5 \%$ at these 3 stations, we can accept that that the simulated attainable yield matches the observed best attainable yield relatively well. This means that the DNDC model with our enriched value set of cultivar parameters is able to simulate rice production level with relatively good accuracy at each of the nine stations.

We do not directly test the DNDC simulations of $\mathrm{CH}_{4}$ and $\mathrm{N}_{2} \mathrm{O}$ emissions against the corresponding field records because there is no observations on $\mathrm{CH}_{4}$ and $\mathrm{N}_{2} \mathrm{O}$ emissions at the nine stations. Instead, we employed the experiment records at the Nanjing station presented in Cai (1997) to validate the performance of the updated DNDC model. The same experiment records were also used to validate the DNDC model by Cai et al. (2003) and Fumuto et al. (2008). We ran DNDC using daily weather, soil and farming management data from Cai et al. (2003) and Fumuto et al. (2008) for the same experimental site. For cultivar parameters, we used the calibrated values at Zhengjiang station, which is $65 \mathrm{~km}$ to the east of Nanjing, on the same Yangtze River bank area. Table 5 compares our results with those of Cai et al. (2003) and Fumuto et al. (2008). Our simulated yield is $7782.5 \mathrm{~kg} \mathrm{ha}^{-1}$, which is $12 \%$ higher than the observed yield. In contrast, there is no yield validation results in Cai et al. (2003) and Fumuto et al. (2008). Our $\mathrm{CH}_{4}$ emission result of $77 \mathrm{~kg} \mathrm{C} \mathrm{ha}^{-1}$ is $1 / 3$ higher than the observed value but still $11 \mathrm{~kg} \mathrm{C} \mathrm{ha}^{-1}$ lower than the result of Fumuto et al. (2008). Our $\mathrm{N}_{2} \mathrm{O}$ emission result of $0.5 \mathrm{~kg} \mathrm{~N} \mathrm{ha}^{-1}$ is much closer to the observed value than that of Cai et al. (2003), which is 8 times higher than the observed value (Table 5).

\subsubsection{Reclassifying the rice cropping zones}

The cropping zone system defines the land use units in the AEZ by climate, soil and terrain characteristics that are relevant to specific crop production. Cropping zones typically represent the spatial distribution of crop cultivars in historical climate conditions (Tian et al., 2012). In this research, the original two-digit rice cropping zone map of China as defined by the AEZ model is employed. There are 14 rice cropping zones. For 9 of these 14 zones, we directly established one-to-one correspondence between the zone and the station within the 
zone. For each of the other 5 zones, the closest suitable cultivar station was chosen for the zone. In this way, we reclassified the existing 14 zones into 9. The map of the reclassified rice cropping zones, overlaid with the paddy field map of China in 2000, is presented in Figure 1.

(Figures 3-7 about here)

\section{RESULTS}

\subsection{The yield prediction performance of the original and updated DNDC models at the} regional level

To show the improvement brought about by the cropping-zone specific enrichment of rice cultivar parameters in terms of yield prediction at the regional level, we ran the DNDC model with both the default and the enriched/updated value set of cultivar parameters across paddy grid-cells for the best single season of rice. The two maps in Figures 3 show the results on yield predictions from the DNDC model by using the default and enriched cultivar parameter values, respectively. The predicted yields in both maps are presented as the averages over 1981-2010. Figure 3-a shows that the single season rice yield is less than $4000 \mathrm{~kg} \mathrm{ha}^{-1}$ in a very large part of the middle and lower reaches of the Yangtze River Basin, which is much lower than observations in this most important rice producing region of China. In sharp contrast, this undesirable gap does not show up in Figure 3-b. In terms of the cropping zone average, the predicted yields in Figure 3-b range from $7000 \mathrm{~kg} \mathrm{ha}^{-1}$ to $10000 \mathrm{~kg}$ $\mathrm{ha}^{-1}$. These results validate our previous argument that using a single set of cultivar parameter values cannot represent the richness of rice cultivars in a large rice producing country like China and can result in poor prediction. This comparison confirms the necessity to calibrate parameter values for more cultivars at multiple representative sites and to employ the enriched parameter values to drive DNDC for the model applications over a large region.

\subsection{Site-level simulations}

The results of site-level simulations under the field management scenario of Traditional Management (TM), Balanced Fertilizer (BF), Midseason Drainage (MD) and Comprehensive Management (CM) are summarized into boxplots as presented in Figures 4 and 5. Figure 4 shows that these four field management methods are able to maintain the best attainable yield under the condition without water and nitrogen stress. Formal $t$-tests also confirm this.

Figures 5-a and 5-b show the results on $\mathrm{CH}_{4}$ and $\mathrm{N}_{2} \mathrm{O}$ emissions, respectively. We first focus on the comparison between TM and BF. The set of boxplots for $\mathrm{CH}_{4}$ does not suggest 
any significant change when moving from TM to BF. For example, at sites HNXY, JXNC and LNTT, the mean $\mathrm{CH}_{4}$ emission decreased by less than $1 \%$ when adopting the balanced fertilizer technique, whereas at other six stations, $\mathrm{CH}_{4}$ emission barely increased, in the range $0.11 \%-4.25 \%$. In contrast, the set of boxplots for $\mathrm{N}_{2} \mathrm{O}$ shows significant mitigation of $\mathrm{N}_{2} \mathrm{O}$ emissions at all stations in relation to the balanced application technique, with reductions in emissions that ranged 10\%-69\% and an average reduction across all sites of 33\%.

Second we compare the results between TM and MD. Figures 5-a and 5-b show that employing midseason drainage irrigation method mitigated $\mathrm{CH}_{4}$ emission significantly, with a reduction ratio ranging $18 \%-39 \%$ and an average reduction across all sites by $25 \%$. However, this new water management measure did not yield consistent results in terms of changes in $\mathrm{N}_{2} \mathrm{O}$ emissions. At sites JSZJ and JXNC, $\mathrm{N}_{2} \mathrm{O}$ emissions in fact increased by $24 \%$ and $20 \%$, respectively, whereas at the other 7 stations, $\mathrm{N}_{2} \mathrm{O}$ emissions decreased in the range 4\%-32\%.

The third comparison is between TM and CM. Figures 5-a and 5-b show significant reductions in both $\mathrm{CH}_{4}(18 \%-40 \%)$ and $\mathrm{N}_{2} \mathrm{O}$ emissions (12\%-60\%). The mitigation impacts of this management scenario outperformed the other scenarios at all nine stations, as a result of positive interactions between the water and fertilizer management measures tested. We further carried out formal $t$-tests to check the level of statistical significance of the differences between TM and CM at each site. The $t$-test results indicate that the reduction of $\mathrm{CH}_{4}$ emission is consistently significant at the $1 \%$ level across all sites, and the reduction of $\mathrm{N}_{2} \mathrm{O}$ is statistically significant at the 5\% (at LNTT site) or 1\% level (at other 7 sites), with the only exception at JXNC.

\subsection{Regional-level simulations}

We extended the simulations of comprehensive mitigation (CM) scenario to the paddy grid-cells in each of the 9 re-classified rice cropping zone to quantify the regional effect of the comprehensive mitigation measure. Figure 6 shows the changes in the predicted yields under the CM scenario versus TM scenario at the grid-cell level. It shows that the CM measure resulted in yield increases in China's major rice producing regions - the Sichuan Basin and the middle and lower reaches of the Yangtze River Basin; yield losses of 5\%-10\% in parts of Northeast China, Ningxia's Hetao irrigation district and the northeast part of Jiangsu province; and no changes or slight yield losses of less than $2 \%$ in other areas. At the same time, the $\mathrm{CM}$ measure led to significant reductions in $\mathrm{CH}_{4}$ and $\mathrm{N}_{2} \mathrm{O}$ emissions (Figure 7), thus resulting in significant decreases in the GHG emission intensity (emissions per unit 
product) of rice.

In terms of total annual $\mathrm{CH}_{4}$ emissions from paddy fields under traditional water and fertilizer management practices, DNDC simulated an annual mean value of $7892 \mathrm{Gg}$ (1 Gg = $10^{9} \mathrm{~g}$ ) C per year over 1981-2010. A nationwide switching from the traditional practice to the comprehensive mitigation measure reduced $\mathrm{CH}_{4}$ emissions by $1940 \mathrm{Gg} \mathrm{C}$, or $25 \%$ in total, and by $8 \%$ to $35 \%$ across most paddy grid-cells, as shown in Figure 7a. The reduction effect was highly significant in the north part of Jiangxi province, large parts of Hunan and Zhejiang provinces and the south part of Anhui province.

In terms of total annual $\mathrm{N}_{2} \mathrm{O}$ emissions under traditional management practices, DNDC simulated an annual mean value of 44 Gg N per year over 1981-2010. The nationwide switch of water and management practice from TM to CM reduced $\mathrm{N}_{2} \mathrm{O}$ emissions by $17 \mathrm{Gg} \mathrm{N}$ or $38 \%$ in total, and by $10 \%$ to $75 \%$ across most paddy grid-cells as shown in Figure $7 \mathrm{~b}$. The most significant mitigation effect was simulated in Northeast China, Jiangsu and Ningxia provinces, while there no significant changes in emissions were simulated in Hubei province.

\section{DISCUSSION AND CONCLUSION}

Our site simulations suggest that comprehensive mitigation measures that combine midseason drainage and balanced fertilizer applications can significantly reduce $\mathrm{CH}_{4}$ and $\mathrm{N}_{2} \mathrm{O}$ emissions from paddy rice fields, without rice yield losses. This result is in line with field experiment results from the Nanjing station presented by Cai et al. (1997). Our site simulations for obtaining a balanced $\mathrm{N}$ fertilizer application ratio highlighted a $25 \%$ excessive application rate in Zhenjiang station of Jiangsu province, very close to the $23.6 \%$ estimate that resulted from the field experiments of Chen et al. (2016) and the 15-25\% estimate made by Hofmeier et al. (2015) in the same province.

Our aggregated results across all paddy fields in China show that mean annual total $\mathrm{CH}_{4}$

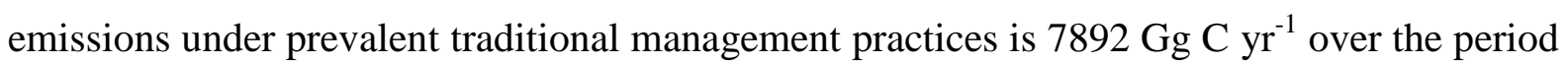
of 1981-2010, well within the range of 6000 to $12000 \mathrm{Gg} \mathrm{C} \mathrm{yr}^{-1}$ simulated by Li et al. (2005) based on DNDC runs using county-level data, but still about double the levels estimated under the IPCC Tier 1 methodology by FAOSTAT (FAOSTAT, 2016). In terms of average $\mathrm{CH}_{4}$ fluxes per hectare under traditional management practices, our result is $186 \mathrm{~kg} \mathrm{C} \mathrm{ha}^{-1} \mathrm{yr}^{-}$ ${ }^{1}$ for the period of 1981-2010, which is in the interval of 9 to $725 \mathrm{~kg} \mathrm{C} \mathrm{ha}^{-1} \mathrm{yr}^{-1}$ indicated by a field validation of the DNDC model in Cai et al. (2003) and the interval of 90 to $214 \mathrm{~kg} \mathrm{C} \mathrm{ha}{ }^{-}$ ${ }^{1} \mathrm{yr}^{-1}$ produced by DNDC simulations at two sites in Liaoning and Jiangsu Provinces (Frolking et al., 2004). Our results also show that the annual total $\mathrm{N}_{2} \mathrm{O}$ emission from paddy 
544 fields under traditional management practices is $43.9 \mathrm{Gg} \mathrm{N} \mathrm{yr}^{-1}$, which is close to the result of 35.7 Gg N as calculated for China's paddy fields as a whole by Gao et al. (2011), but significantly lower than the simulation results of 290 to $410 \mathrm{Gg} \mathrm{N} \mathrm{yr}^{-1}$ as presented in Li et al. (2005). In terms of average $\mathrm{N}_{2} \mathrm{O}$ fluxes per hectare per year under the traditional management practice, our result is $1.04 \mathrm{~kg} \mathrm{~N} \mathrm{ha}^{-1} \mathrm{yr}^{-1}$ during 1981-2010, which is located in the interval of 0.14 to $4.42 \mathrm{~kg} \mathrm{~N} \mathrm{ha}^{-1} \mathrm{yr}^{-1}$ as reported in Akiyama et al. (2005) based on the a summary of the observed data.

The contribution of this research is not limited to confirming the existing assessments on $\mathrm{CH}_{4}$ and $\mathrm{N}_{2} \mathrm{O}$ inventories. It aims to quantify, at both the site and regional levels, the extent to which the major alternative water and fertilizer management methods can lead to significant reduction of $\mathrm{CH}_{4}$ and $\mathrm{N}_{2} \mathrm{O}$ emissions without causing yield reduction. For this purpose, this research enriches the value set of cultivar parameters of the DNDC model by effectively communicating with the DSSAT-rice model and the AEZ model, and up-scales the DNDC runs within each of the AEZ rice cropping zones.

More importantly, our systematic assessment focused on the effect of comprehensive mitigation measures, which combines a balanced fertilizer application approach with the midseason field drying method, and their evaluation against corresponding impacts on food production potential. Our results show that switching from traditional fertilizer and water management practices to comprehensive mitigation measures can lead to significant reductions in both $\mathrm{CH}_{4}$ and $\mathrm{N}_{2} \mathrm{O}$ emissions. $\mathrm{CH}_{4}$ emission can be reduced by $18-40 \%$ across the nine representative stations, by 8-35\% across almost all paddy grid-cells of China, and by $25 \%$ at the national level. $\mathrm{N}_{2} \mathrm{O}$ emission can be reduced by $12-60 \%$ across the nine representative sites, by $10-75 \%$ across a vast majority of grid-cells in China's paddy fields, and by $38 \%$ at the national level. These findings indicate that there is significant room for reducing GHG emissions in the Chinese rice producing sector. Measures such as midseason drainage and balanced fertilization, based on crop requirements and soil testing, can achieve the triple benefits of maintaining or even in some cases increasing production, while lowering agricultural input costs and reducing GHG emissions. In future research, more mitigation management methods, such as alternate wetting and drying water management for rice (AWD), and returning straw and zero tillage, could be evaluated at both site and regional scale, providing the necessary observation records become available for model calibration.

Several limitations characterize this study, some of them generically applicable to all similar modeling exercises involving up-scaling in space from experimental field station results. These include uncertainty in many of the assumptions used to distribute local weather, 
578 soil and management parameters information over grid-cells. Two limitations are specific to 579 this study of paddy rice in China. First, only the most important single rice rotation was 580 considered, while double cropping rice was not studied. This may lead to biased estimation 581 because single cropping system typically require less $\mathrm{N}$ fertilizer, with weaker soil 582 denitrification reactions in cases where there is no additional crop and fertilizer inputs in the 583 fallow season. Future studies should investigate GHG emissions dynamics in double rice 584 cropping systems and other rotations with rice. Second, although the nine stations we chose 585 are representative at the two-digit cropping zone level, cultivar differences are present even 586 within individual two-digit cropping zones. The methodology presented in this research will 587 nonetheless be applicable to introduce more local rice cultivars into the DNDC model. 


\section{References}

Abdalla, M., Kumar, S., Jones, M., Burke, J., Williams, M., 2011. Testing DNDC model for simulating soil respiration and assessing the effects of climate change on the $\mathrm{CO}_{2}$ gas flux from Irish agriculture. Global Planet. Change 78, 106-115.

Akiyama, H., Yagi, K., Yan, X., 2005. Direct N2O emissions from rice paddy fields: summary of available data. Global Biogeochem. Cycles 19, GB1005.

Alley, R.B., Marotzke, J., Nordhaus, W.D., Overpeck, J.T., Peteet, D.M., Pielke, R.A., et al., 2003. Abrupt Climate Change. Science 299, 2005-2010.

Batjes, N. H., 2009. Harmonized soil profile data for applications at global and continental scales: updates to the WISE database. Soil Use Manage. 25, 124-127.

Beheydt, D., Boeckx, P., Sleutel, S., Li, C., van Cleemput, O., 2007. Validation of DNDC for 22 longterm $\mathrm{N}_{2} \mathrm{O}$ field emission measurements. Atmos. Environ. 41, 6196-6211.

Beven, K., Freer, J., 2001. Equifinality, data assimilation, and uncertainty estimation in mechanistic modelling of complex environmental systems using the GLUE methodology. J. Hydrol. 249, 1129.

Blasone, R.S., Vrugt, J.A., Madsen, H., et al. 2008. Generalized likelihood uncertainty estimation (GLUE) using adaptive Markov chain Monte Carlo sampling. Adv Water Resour 31(4): 630-648.

Cai, Z., Xing, G., Yan, X., Xu, H., Tsuruta, H., Yagi, K., Minami K., 1997. Methane and nitrous oxide emissions from rice paddy fields as affected by nitrogen fertilizers and water management. Plant Soil 196, 7-14.

Cai, Z., Sawamoto, T., Li, C., Kang, G., Boonjawat, J., Mosier, A., et al., 2003. Field validation of the DNDC model for greenhouse gas emissions in East Asian cropping systems. Global Biogeochem. Cycles 17 GB1107.

Challinor, A. J., Watson, J., Lobell, D. B., Howden, S. M., Smith, D. R., Chhetri. N. 2014. A metaanalysis of crop yield under climate change and adaptation. Nature Clim. Change 4:287-291. DOI: 10.1038/nclimate2153.

Chen, H., Yu, C., Li, C., Xin, Q., Huang, X., Zhang, J., et al., 2016. Modeling the impacts of water and fertilizer management on the ecosystem service of rice rotated cropping systems in China. Agric. Ecosyst. Environ. 219, 49-57.

Dong, H., Yao, Z., Zheng, X., Mei, B., Xie, B., Wang, R., et al., 2011. Effect of ammonium-based, non-sulfate fertilizers on $\mathrm{CH}_{4}$ emissions from a paddy field with a typical Chinese water management regime. Atmos. Environ. 45, 1095-1101.

FAO, 2007. Mapping Biophysical Factors That Influence Agricultural Production and Rural Vulnerability. Environment and Natural Resources Series 10. FAO, Rome, Italy.

FAO, 2016. Rice Market Monitor, April 2016. Trade and Markets Division, Food and Agriculture Organization of the United Nations, Rome. Available at http://www.fao.org/fileadmin/templates/est/COMM_MARKETS_MONITORING/Rice/Images/ 
RMM/RMM_APR16.pdf.

FAO/IIASA/ISRIC/ISSCAS/JRC, 2009. Harmonized World Soil Database (version 1.1). FAO, Rome, Italy and IIASA, Laxenburg, Austria.

FAOSTAT, 2016. Emissions-Agriculture Domain. http://www.fao.org/faostat/en/\#data/GR/visualize

Fischer, G., Nachtergaele, F., Prieler, S., Teixeira, E., van Velthuizen, H.T., Tóth, G., et al., 2012. Global Agro-Ecological Zones (GAEZ v3.0): Model Documentation. IIASA and FAO, Laxenburg, Austria and Rome, Italy.

Fischer, G., Shah, M., Tubiello, F.N., van Velthuizen, H.T., 2005. Socioeconomic andclimate change impacts on agriculture: an integrated assessment, 1990-2080.Philosophical Transactions of the Royal Society B 360, 2067-2073.

Frolking, S., Li, C., Braswell, R., Fuglestvedt, J., 2004, Short- and long-term greenhouse gas and radiative forcing impacts of changing water management in Asian rice paddies. Glob. Chang. Bio. 10, 1180-1196.

Fumoto, F., Kobayashi, K., Li, C., Yagi, K., and Hasegawa, T., 2008. Revising a process-based biogeochemistry model (DNDC) to simulate methane emission from rice paddy fields under various residue management and fertilizer regimes. Glob. Change Biol. 14, 382-402.

Gao, B., X. T. Ju, Q. Zhang, P. Christie, F. S. Zhang, 2011. New estimates of direct N2O emissions from Chinese croplands from 1980 to 2007 using localized emission factors. Biogeosciences, 8, 3011-3024.

Gao, M.F., Qiu, J.J., Li, C.S., Wang, L.G., Li, H., Gao, C.L., 2014. Modeling nitrogen loading from a watershed consisting of cropland and livestock farms in China using Manure-DNDC. Agr. Ecosyst. Environ. 185, 88-98.

Gijsman, A.J., Jagtap, S.S., Jones, J.W., 2002. Wading through a swamp of complete confusion: how to choose a method for estimating soil water retention parameters for crop models. European Journal of Agronomy 18, 75-105.

Gijsman, A.J., Thornton, P.K., Hoogenboom, G., 2007. Using the WISE database to parameterize soil inputs for crop simulation models. Computers and Electronics in Agriculture 56, 85-100.

Gilhespy, S.L., Anthony, S., Cardenas, L., Chadwick, D., Pardo A., Li, C., et al., 2014. First 20 years of DNDC (DeNitrification DeComposition): Model evolution. Ecol. Model. 292, 51-62.

Giltrap, D., Li, C., Saggar, S., 2010. DNDC: A process-based model of greenhouse gas fluxes from agricultural soils. Agr. Ecosyst. Enviro. 136, 292-300.

Gohari, A., Eslamian, S., Abedi-Koupaei, J., Bavani, A.M., Wang, D., Madani, K., 2013.Climate change impacts on crop production in Iran's Zayandeh-Rud River Basin.Science of the Total Environment 442, 405-419.

He, J., Jones, J., Graham, W., Dukes, M., 2010. Influence of likelihood function choice for estimating crop model parameters using the generalized likelihood uncertainty estimation method. Agr. Syst. 103, 256-264. 
Hofmeier, M., Roelcke, M., Han, Y., Lan, T., Bergmann, H., Böhm, D., et al., 2015. Nitrogen management in a rice-wheat system in the Taihu Region: recommendations based on field experiments and surveys. Agric. Ecosyst. Environ. 209, 60-73.

Hoogenboom G, Jones JW, Wilkens PW, et al. 2010. Decision Support System for Agro-technology Transfer, Version 4.5, Volume 1: Overview. University of Hawaii, Honolulu, USA.

IPCC, 2006. IPCC Guidelines for National Greenhouse Gas Inventories, Inst. for Global Environ. Strategies, Hayama, Japan.

IPCC, 2013. Climate Change 2013: The Physical Science Basis. Contribution of Working Group I to the Fourth Assessment Report of the Intergovernmental Panel on Climate Change. Cambridge Univ. Press. Cambridge.

IPCC, 2014. Climate Change 2014: Summary for Policymakers. Contribution of Working Group III to the Fourth Assessment Report of the Intergovernmental Panel on Climate Change. Cambridge Univ. Press. Cambridge.

Itoh, M., Sudo, S., Mori, S., Saito, H., Yoshida, T., Shiratori, Y., et al., 2011. Mitigation of methane emissions from paddy fields by prolonging midseason drainage. Agric. Ecosyst. Environ. 141, 359-372.

Johnson-Beebout, E. S., Angeles, R. O., Alberto, R. M. C., Buresh, J. R., 2009. Simultaneous minimization of nitrous oxide and methane emission from rice paddy soils is improbable due to redox potential changes with depth in a greenhouse experiment without plants. Geoderma. 149, 45-53.

Jones, W. J., Antle, M. J., Basso, B., Boote, J. K., Conant, T. R., Foster, I., et al., 2016. Brief history of agricultural systems modeling. Agr Syst. http://dx.doi.org/10.1016/j.agsy.2016.05.014)

Jones, J.W., Hoogenboom, G., Porter, C.H., Boote, K.J., Batchelor, W.D., Hunt, L.A., et al., 2003. The DSSAT cropping system model. Europ. J. Agronomy 18, 235-265.

Karl, T.R., Trenberth, K.E., 2003. Modern Global Climate Change. Science 302, 1719-1723.

Lane, L. J., 1982. Distributed model for small semi-arid watersheds. 3. Hydr. Div. Am. Soc. Civ. Eng. 108, 1114-1131.

Li, C., 2000. Modeling trace gas emissions from agricultural ecosystems. Nutr. Cycl. Agroecosys. 58, 259-276.

Li, C., 2007. Quantifying greenhouse gas emissions from soils: scientific basis and modeling approach. Soil Sci. Plant Nutr. 53, 344-352.

Li, C., Frolking, S., Harriss, R., 1994. Modeling carbon biogeochemistry in agricultural soils. Global Biogeochem. Cycles 8, 237-254.

Li, C., Frolking, S., Frolking, T.A., 1992. A model of $\mathrm{N}_{2} \mathrm{O}$ evolution from soil driven by rainfall events: 1. Model structure and sensitivity. J. Geophys. Res. 97, 9759-9776.

Li, C., Frolking, S., Xiao, X., Moore, B., Boles, S., Qiu, J., et al., 2005. Modeling impacts of farming 
management alternatives on $\mathrm{CO}_{2}, \mathrm{CH}_{4}$, and $\mathrm{N}_{2} \mathrm{O}$ emissions: A case study for water management of rice agriculture of China. Global Biogeochem. Cycles 19, GB3010.

Li, C., Salas, W., Zhang, R., Krauter, C., Rotz, A., and Mitloehner, F., 2012. Manure-DNDC: a biogeochemical process model for quantifying greenhouse gas and ammonia emissions from livestock manure systems. Nutr. Cycl. Agroecos. 93, 163-200, doi: 10.1007/s10705-012-9507-z, 2012.

Liu, J., Liu, M., Tian, H., Zhuang, D., Zhang, Z., Zhang, W., et al., 2005. Spatial and temporal patterns of China's cropland during 1990-2000: an analysis based on Landsat TM data. Remote Sensing of Environment 98, 442-456.

Masutomi, Y., Takahashi, K., Harasawa, H., Matsuoka, Y., 2009. Impact assessmentof climate change on rice production in Asia in comprehensive considerationof process/parameter uncertainty in general circulation models. Agriculture,Ecosystems and Environment 131, 281-291.

McCuen, R.H., 2003. Modeling Hydrologic Change: Statistical Methods. Lewis Publishers, New York.

Miao, Y., Stewart, B.A., Zhang, F., 2010. Long-term experiments for sustainable nutrient management in China. A review. Agron. Sustain. Dev. 31, 397-414.

Pathak, H., Li, C., Wassmann, R., 2005. Greenhouse gas emissions from Indian rice fields: calibration and upscaling using the DNDC model. Biogeosciences 2, 113-123.

Penning de Vries, F., Teng, P., Metselaar, K., Hunt, L.A., 1992. Designing Improved Plant Types: A Breeder’s Viewpoint, Systems Approaches for Agricultural Development, vol. 2. Springer, Netherlands, pp. 3-17.

Pohlert, T., 2004. Use of empirical global radiation models for maize growth simulation. Agricultural and Forest Meteorology 126, 47-58.

Prasada Rao, G.S.L.H.V. 2008. Agricultural Meteorology, PHI Learning Pvt. Ltd., Delhi.

Ritchie, J.T., Godwin, D.C., Singh, U., 1989. Soil and Water inputs for IBSNAT crop models, In DSSAT, IBSNAT Symposium, Part I, Las Vegas, Nevada.

Seidl, M., Batchelor, W., Fallick, J., Paz, J., 2001. GIS-crop model based decision support system to evaluate corn and soybean prescriptions. Appl. Eng. Agric. 17, 721-728.

Smith, P., Trines, E., 2007. Agricultural measures for mitigating climate change: will the barriers prevent any benefits to developing countries? Int. J. Agric. Sust. 4, 173-175.

Smith, P., 2012. Agricultural greenhouse gas mitigation potential globally, in Europe and in the UK: what have we learnt in the last 20 years? Glob. Chang. Biol. 18, 35-43.

Tang, H.J., Qiu, J.J., Van Ranst, E., Li, C.S. 2006. Estimations of soil organic carbon storage in cropland of China based on DNDC model. Geoderma 134, 200-206.

Thorp, K., DeJonge, K., Kaleita, A., Batchelor, W., Paz, J., 2008. Methodology for the use of DSSAT models for precision agriculture decision support. Comput. Electron. Agr. 64, 276-285.

Tian, Z., Zhong, H., Shi R., Sun, L., Fischer, G., Liang, Z., 2012. Estimating potential yield of wheat production in China based on cross-scale data-model fusion. Front Earth Sci. 6, 364-372. 
Tian, Z., Zhong, H., Sun, L., Fischer, G., van Velthuizen, H., Liang, Z. 2014. Improving performance of Agro-Ecological Zone (AEZ) modeling by cross-scale model coupling: An application to japonica riceproduction in Northeast China. Ecological Modelling 290, 155-164.

Tonitto, C., David, M.B., Drinkwater, L.E., Li, C.S., 2007. Application of the DNDC model to tiledrained Illinois agroecosystems: model calibration, validation, and uncertainty analysis. Nutr. Cycl. Agroecosys. 78, 51-63.

Tubiello, F.N., Fischer, G., 2007. Reducing climate change impacts on agriculture:global and regional effects of mitigation, 2000-2080. Technological Forecastingand Social Change 74, 1030-1056.

Verburg, P.H., Chen, Y., Veldkamp, T., 2000. Spatial explorations of land use change and grain production in China. Agric. Ecosyst. Environ. 82, 333-354.

Wang, G., Chen, S. 2012. A review on parameterization and uncertainty in modeling greenhouse gas emissions from soil. Geoderma 170, 206-216.

Wang, L.G., Qiu, J.J., Tang, H.J., Li, H., Li, C.S., van Ranst, E. 2008. Modelling soil organic carbon dynamics in the major agricultural regions of China. Geoderma 147, 47-55.

Wang, S., Huang, G.H., Huang, W., et al. 2015. A fractional factorial probabilistic collocation method for uncertainty propagation of hydrologic model parameters in a reduced dimensional space. $\mathrm{J}$ Hydrol 529: 1129-1146.

Wu, F., Zhang, H., Li, L., Chen, F., Huang, F., Xiao, X., 2008. Characteristics of $\mathrm{CH}_{4}$ emission and greenhouse effects in double paddy soil with conservation tillage. Scientia Agricultura Sinica 41, 2703-2709.

Yan, X., Akiyama, H., Yagi, K., Akimoto, H., 2009. Global estimations of the inventory and mitigation potential of methane emissions from rice cultivation conducted using the 2006 Intergovernmental Panel on Climate Change Guidelines. Global Biogeochem. Cycles 23, GB2002.

Zhang, L., Zhuang, Q., Li, X., Zhao, Q., Yu, D., Liu, Y., et al. 2016. Carbon sequestration in the uplands of Eastern China: An analysis with high-resolution model simulations. Soil \& Tillage Research 158, 165-176.

Zhang, Y., Li, C., Trettin, C. C., Li, H., and Sun, G., 2002. An integrated model of soil, hydrology and vegetation for carbon dynamics in wetland ecosystems, Global Biogeochem. Cy. 16, 1061, doi: 10.1029/2001GB001838. 
Table 1. Information of the nine representative observation stations

\begin{tabular}{|c|c|c|c|c|c|}
\hline Site & Location & Soil texture & $\begin{array}{l}\text { Mean daily } \\
\text { temperature range } \\
\left({ }^{\circ} \mathrm{C}\right)\end{array}$ & $\begin{array}{l}\text { Precipitation } \\
\text { range }(\mathrm{mm})\end{array}$ & $\begin{array}{l}\text { Mean } \\
\text { precipitation } \\
(\mathrm{mm})\end{array}$ \\
\hline AHHF & $31.87^{\circ} \mathrm{N} 117.23^{\circ} \mathrm{E}$ & Loam & $24.2-27.3$ & 228.4-1064.2 & 578.6 \\
\hline HNXY & $32.12^{\circ} \mathrm{N} 114.08^{\circ} \mathrm{E}$ & Silty-clay & $24.2-27$ & 151.7-1161.4 & 677.0 \\
\hline JLYJ & $42.88^{\circ} \mathrm{N} 129.47^{\circ} \mathrm{E}$ & Clay-loam & $15.2-18.4$ & $331.7-790.0$ & 467.4 \\
\hline JSZJ & $32.18^{\circ} \mathrm{N} 119.47^{\circ} \mathrm{E}$ & Clay-loam & $25-27.1$ & 269.8-1327.0 & 669.1 \\
\hline JXNC & $28.55^{\circ} \mathrm{N} 115.95^{\circ} \mathrm{E}$ & Clay-loam & 23-25.6 & 501.4-1341.2 & 820.2 \\
\hline LNTT & $41.42^{\circ} \mathrm{N} 123.32^{\circ} \mathrm{E}$ & $\begin{array}{l}\text { Sandy-clay- } \\
\text { loam }\end{array}$ & $19-22.3$ & 354.1-916.3 & 569.5 \\
\hline SCCD & $30.7^{\circ} \mathrm{N} 103.83^{\circ} \mathrm{E}$ & Clay-loam & $22-24.1$ & 488.1-1050.2 & 733.8 \\
\hline SDLY & $35.05^{\circ} \mathrm{N} 118.35^{\circ} \mathrm{E}$ & Clay-loam & $22.5-24.9$ & $441.8-1106.7$ & 715.6 \\
\hline GDGZ & $23.05^{\circ} \mathrm{N} 113.47^{\circ} \mathrm{E}$ & Clay-loam & $18.9-25.8$ & $570.1-1640.7$ & 1012.5 \\
\hline
\end{tabular}

Notes: The statistics on temperature and precipitation is for the single rice growing season over the period of 1981-2010.

Table 2. Observed level of fertilizer application and the balanced fertilizer ratio (BFR) at the nine stations

\begin{tabular}{lccccccccc}
\hline Site & AHHF & HNXY & JLYJ & JSZJ & JXNC & LNTT & SCCD & SDLY & GDGZ \\
\hline $\begin{array}{l}\text { Fertilizer App } \\
\left.\text { (kgN ha }{ }^{-1}\right)\end{array}$ & 335.0 & 255.3 & 330.5 & 273.0 & 334.5 & 203.6 & 252.9 & 186.0 & 250.0 \\
BFR-1 (\%) & 85 & 80 & 65 & 75 & 90 & 80 & 95 & 70 & 65 \\
BFR-2 (\%) & 85 & 80 & 65 & 75 & 80 & 95 & 95 & 70 & 65 \\
\hline
\end{tabular}

Notes: BFR-1 refers to the BFR under continues flooding scenario and BFR-2 under the midseason drainage and 
Table 3. Calibrated values of cultivar parameters for DNDC at the nine representative sites

\begin{tabular}{lccccccccc}
\hline Site & GB & HI & GF & LF & SF & RF & ND & OT & TDD \\
\hline AHHF & 11436.33 & 0.5273 & 0.448 & 0.201 & 0.201 & 0.15 & 209.588 & 27 & 3859.00 \\
HNXY & 11597.39 & 0.5179 & 0.440 & 0.205 & 0.205 & 0.15 & 215.382 & 25 & 3776.00 \\
JLYJ & 10761.25 & 0.5311 & 0.452 & 0.199 & 0.199 & 0.15 & 168.919 & 22 & 2965.00 \\
JSZJ & 11539.50 & 0.5078 & 0.432 & 0.209 & 0.209 & 0.15 & 217.479 & 25 & 3884.30 \\
JXNC & 9055.58 & 0.6058 & 0.514 & 0.168 & 0.168 & 0.15 & 150.094 & 30 & 2594.95 \\
SCCD & 9883.21 & 0.5644 & 0.480 & 0.185 & 0.185 & 0.15 & 172.349 & 25 & 3873.80 \\
SDLY & 9900.00 & 0.4958 & 0.422 & 0.214 & 0.214 & 0.15 & 158.480 & 25 & 3808.60 \\
LNTT & 9528.57 & 0.5521 & 0.470 & 0.190 & 0.190 & 0.15 & 146.662 & 22 & 3471.55 \\
GDGZ & 7801.40 & 0.5486 & 0.466 & 0.192 & 0.192 & 0.15 & 138.883 & 30 & 3351.45 \\
\hline
\end{tabular}

784

785

786

787

788

789

790

791 792

Notes: GB denotes grain biomass (kg/ha/yr), HI harvest index, GF grain-fraction, LF leaf-fraction, SF stemfraction, RF root-fraction, ND $\mathrm{N}$ demand (kgN/ha/yr), OT optimum temperature $\left({ }^{\circ} \mathrm{C}\right)$, TDD accumulative degree days from emergence to maturity $\left({ }^{\circ} \mathrm{C}\right)$.

Table 4. The observed best attainable yield, the minimum, mean, and maximum of the simulated yields, and the average RAE at the nine stations (1981-2010)

\begin{tabular}{cccccc}
\hline \multirow{2}{*}{ Site } & $\begin{array}{c}\text { Observed yield } \\
(\mathrm{kg})\end{array}$ & \multicolumn{2}{c}{ Simulated attainable yield (kg) } & Average RAE \\
\cline { 3 - 4 } & 10,815 & Minimum & mean & maximum & \\
\hline AHHF & 10,024 & 9,869 & 10,266 & 10,952 & 5.086 \\
HNXY & 10,500 & 9,249 & 10,125 & 10,992 & 0.998 \\
JLYJ & 10,140 & 8,891 & 10,4909 & 10,381 & 4.686 \\
JSZJ & 8,812 & 8,268 & 8,623 & 10,852 & 3.491 \\
JXNC & 9,240 & 8,861 & 9,240 & 9,531 & 2.156 \\
SCCD & 8,580 & 8,893 & 9,242 & 9,582 & 0.000 \\
SDLY & 9,184 & 8,276 & 8,752 & 9,195 & 7.716 \\
LNTT & 6,945 & 7,235 & 7,511 & 7,677 & 8.135 \\
GDGZ & & & & & \\
\hline
\end{tabular}


796 Table 5. Rice yield, $\mathrm{CH}_{4}$ and $\mathrm{N}_{2} \mathrm{O}$ emissions at the Nanjing site in 1994.

\begin{tabular}{|c|c|c|c|c|}
\hline & \multirow{2}{*}{$\begin{array}{l}\text { Observed (Cai et } \\
\text { al., 2003) }\end{array}$} & \multicolumn{3}{|c|}{ Simulated with DNDC } \\
\hline & & Our results & Cai et al. (2003) & Fumuto et al. (2008) \\
\hline Yield $\left(\mathrm{kg} \mathrm{ha}^{-1}\right)$ & 6918.8 & 7782.5 & & \\
\hline $\mathrm{CH}_{4}\left(\mathrm{~kg} \mathrm{C} \mathrm{ha}{ }^{-1}\right)$ & 57.8 & 77 & 47.1 & 88 \\
\hline $\mathrm{N}_{2} \mathrm{O}\left(\mathrm{kg} \mathrm{N} \mathrm{ha}^{-1}\right)$ & 0.62 & 0.5 & 5.70 & \\
\hline
\end{tabular}

797 Note: Observation records and simulation results are for the same single rice growing season in 1994. 


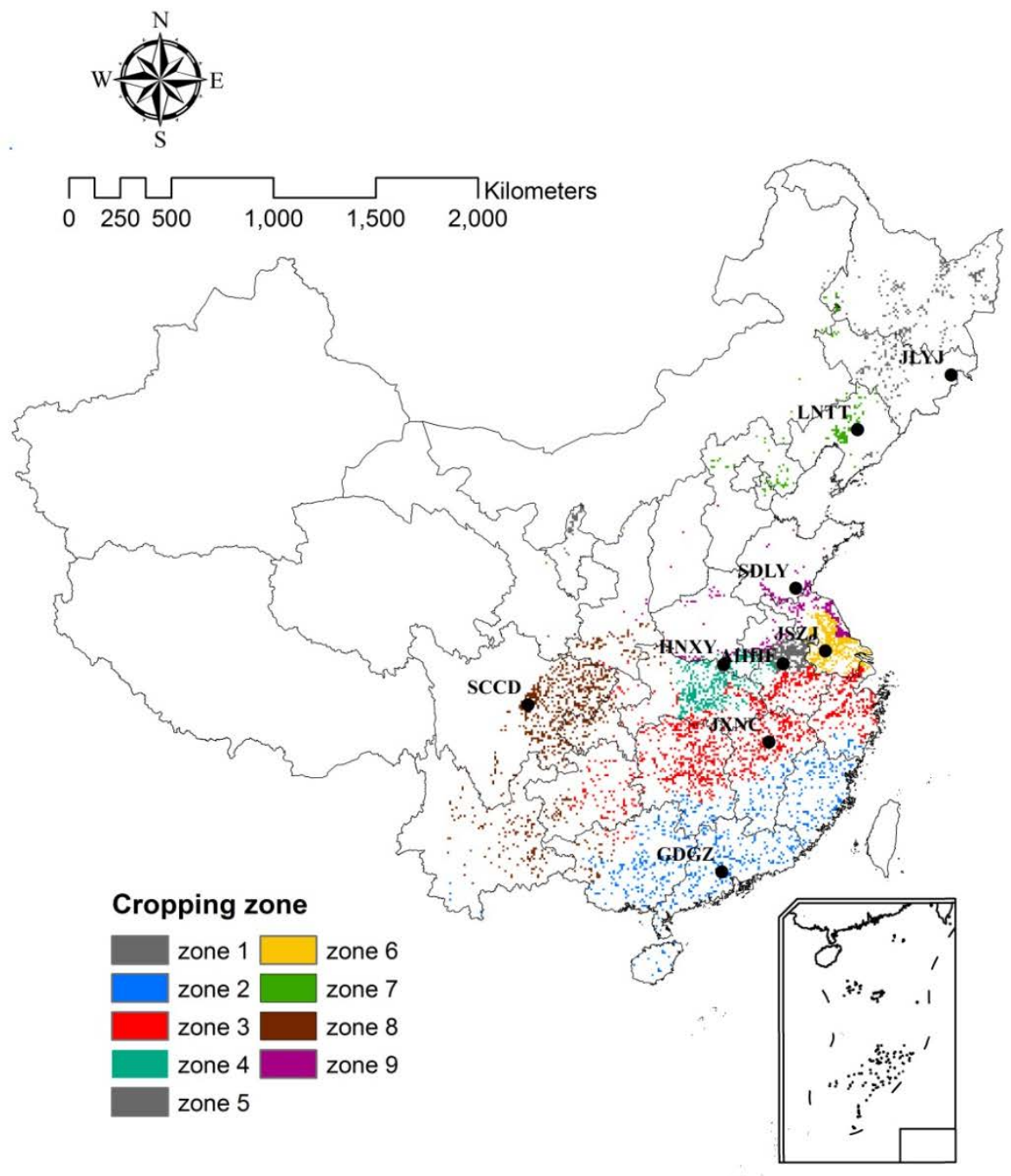

Figure 1. The reclassified rice cropping zone map of China based on 9 observation stations. 


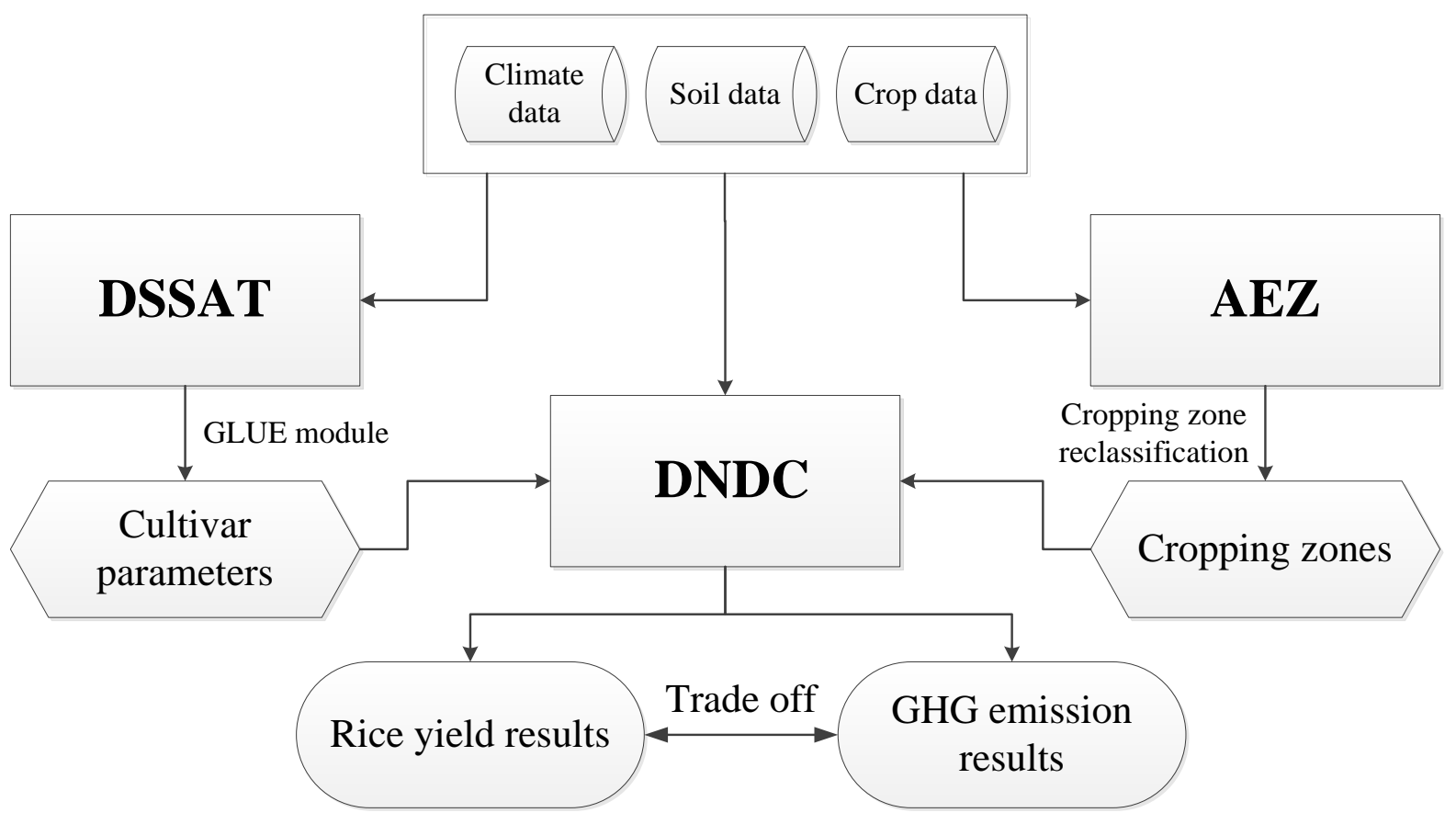

Figure 2. Flowchart of the model coupling procedure 

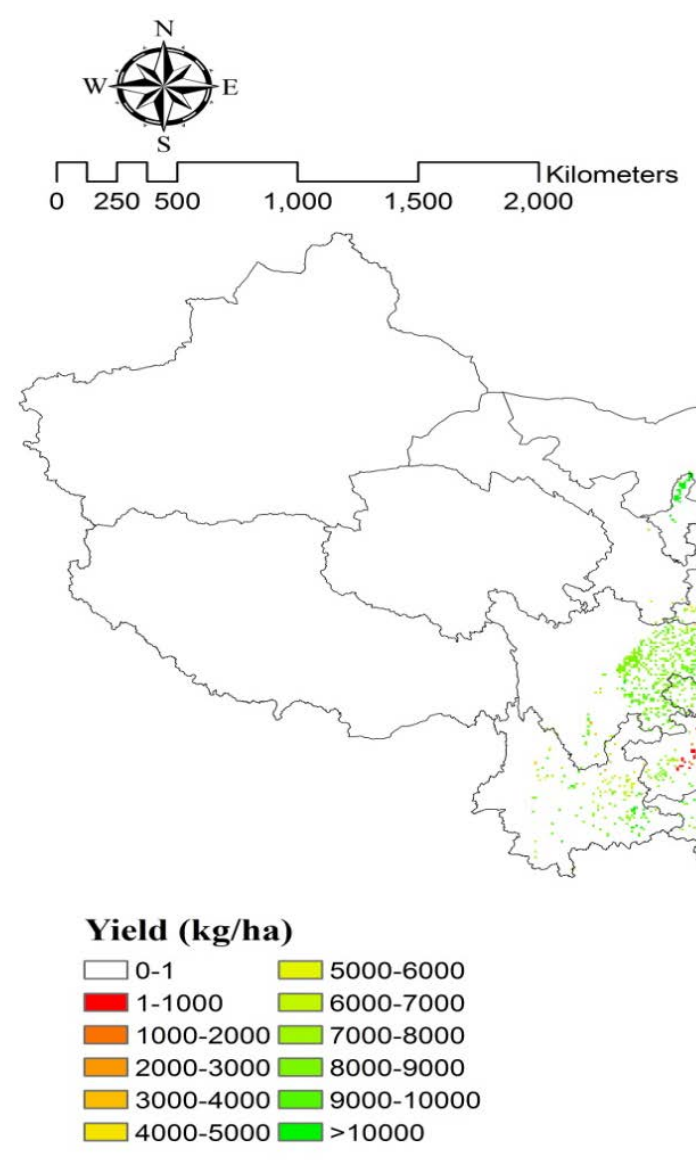

816

817

Figure 3. The grid-cell results of rice yield simulation from the original DNDC (left, denoted as Figure 3-a) and coupled DNDC (right, Figure 3-

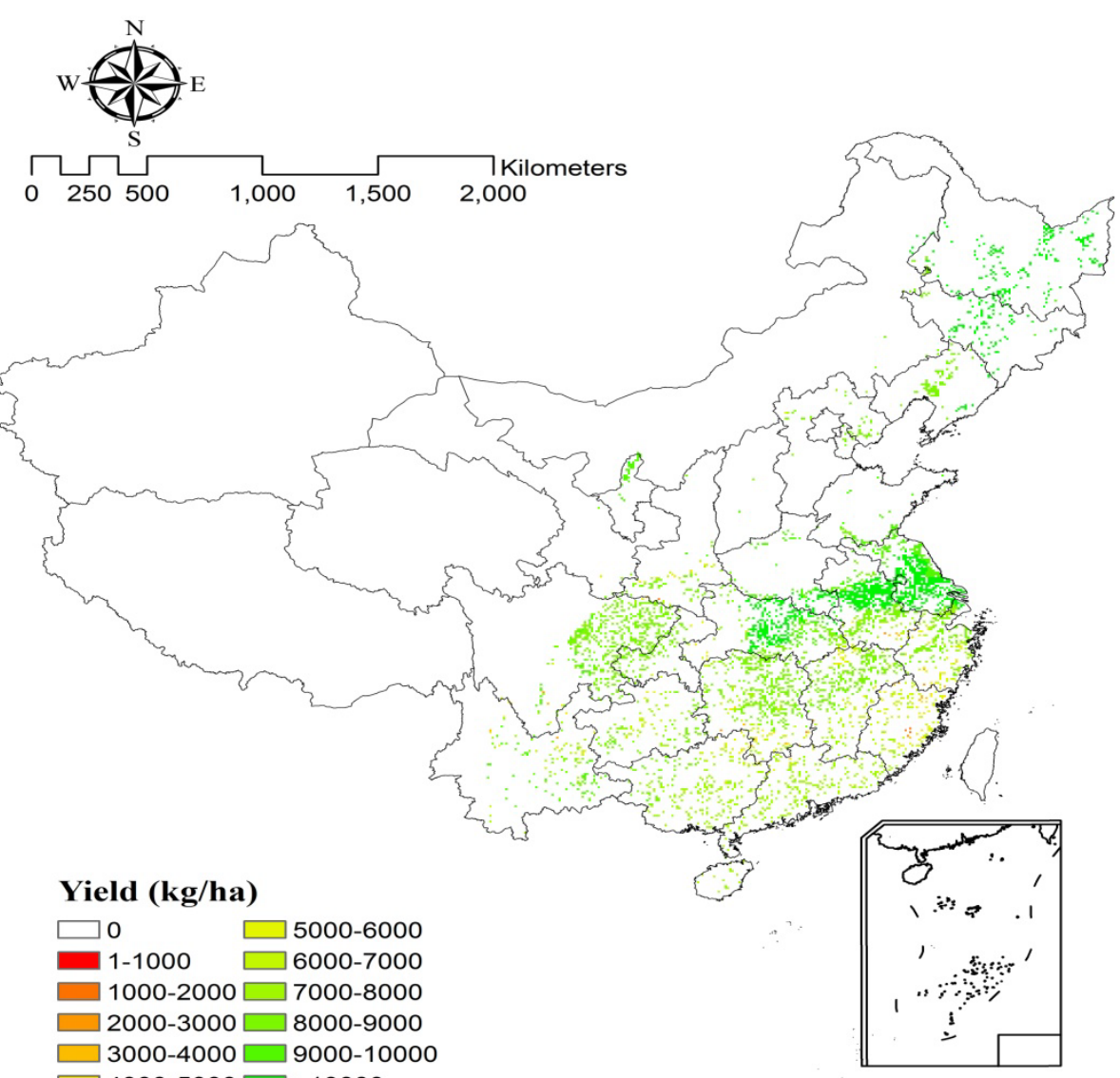

$\square 3000-4000 \square 9000-10$

$\square$ 4000-5000 $\square>10000$

818 b) model, average over 1981-2010 
This accepted version of an article published by online by Elsevier on 25 April 2017 in Agricultural Systems. Published version available from: https://doi.org/10.1016/j.agsy.2017.04.006

Accepted version made available under CC-BY-NC-ND 4.0 International License from SOAS Research Online: http://eprints.soas.ac.uk/24041/

820

821

\section{Rice yield under different field manac}

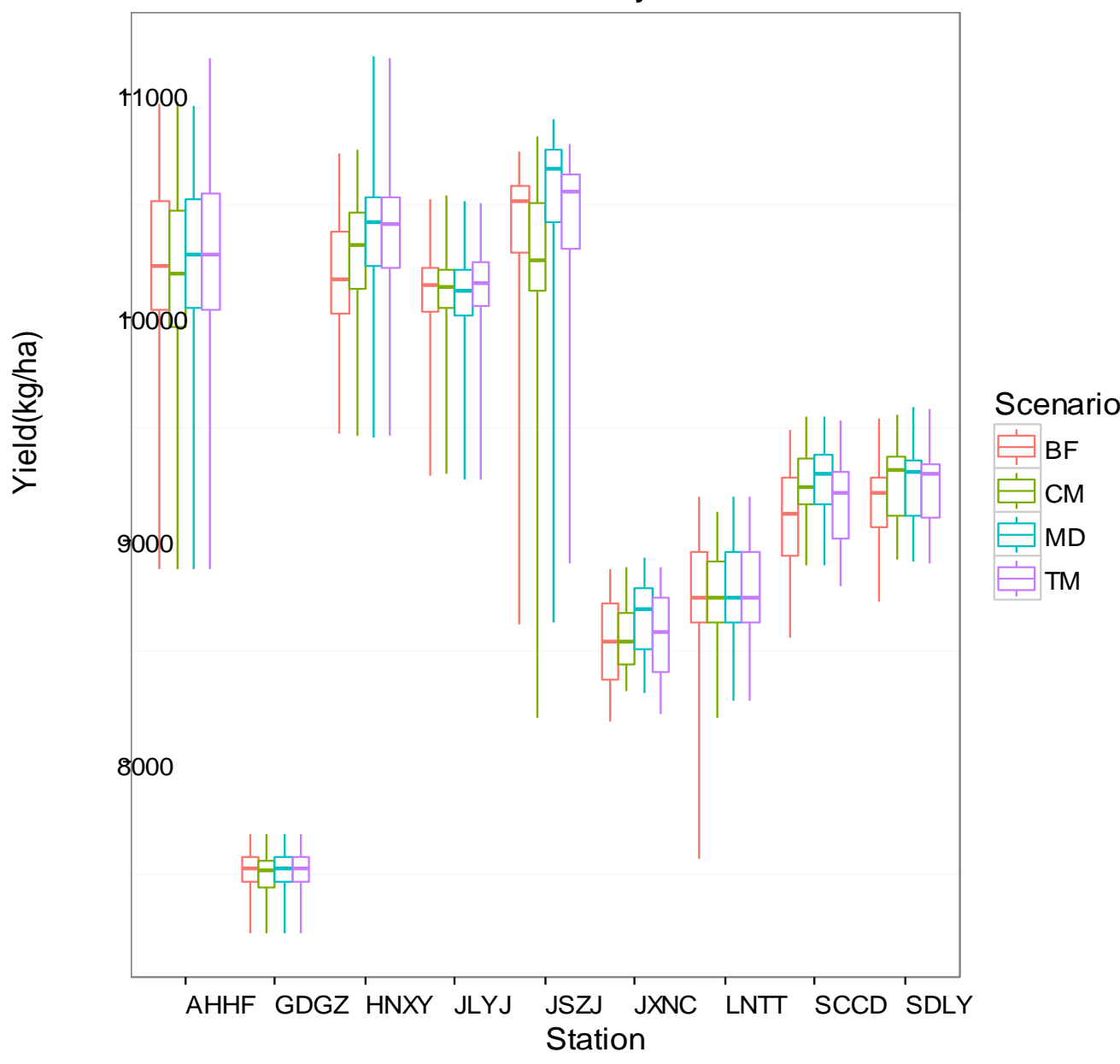

Figure 4. The boxplots of rice yields under field management scenarios of Traditional Management (TM), Balanced Fertilizer (BF), Midseason Drainage (MD) and Comprehensive Management (CM). 

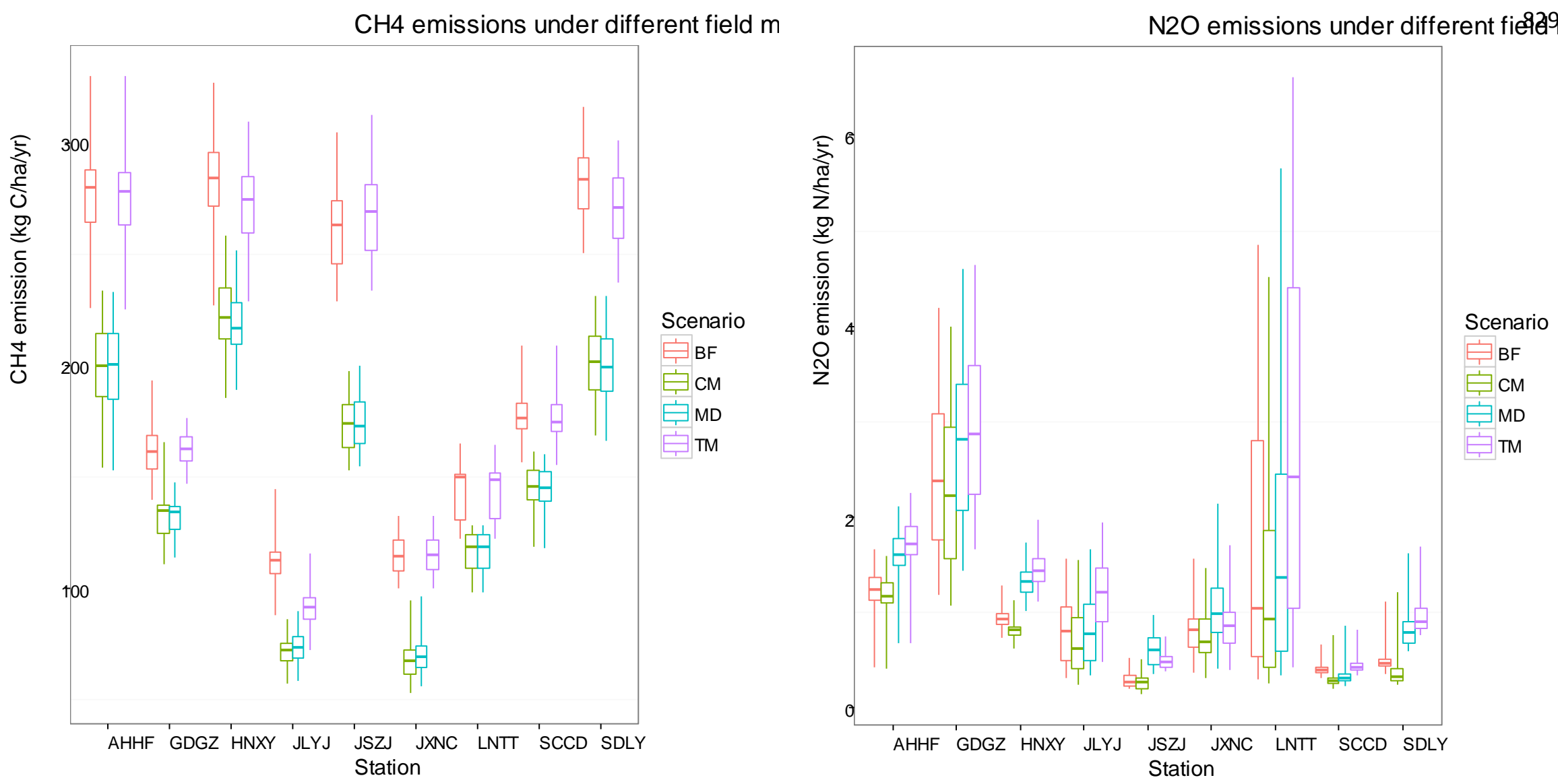

Figure 5. The boxplots of methane emission (left, denoted as Figure 5-a.) and nitrous oxide emission (right, Figure 5-b.) under field management scenarios of Traditional Management (TM), Balanced Fertilizer (BF), Midseason Drainage (MD) and Comprehensive Management (CM). 


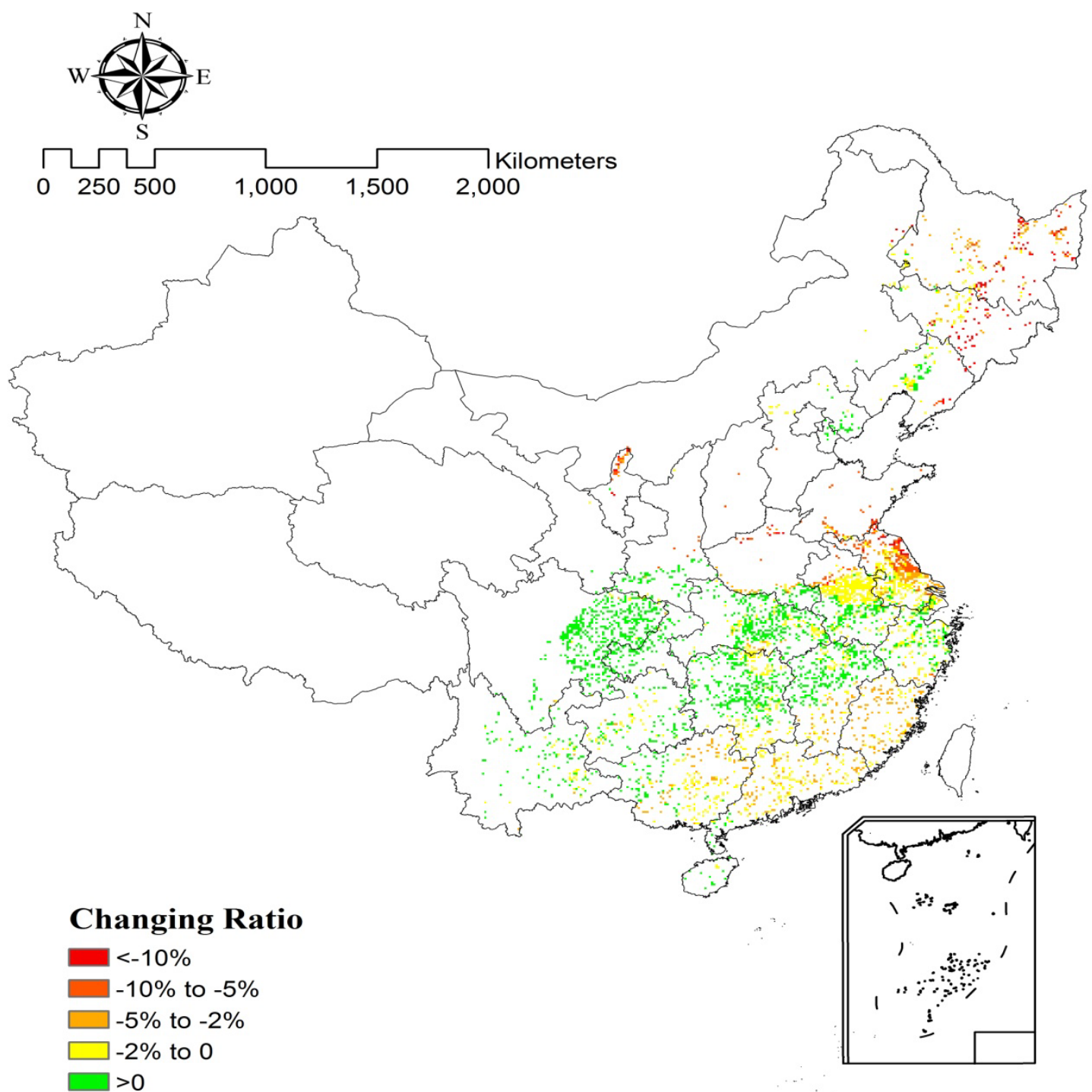

Figure 6. Changes of the simulated best attainable yields at the grid-cell level under the comprehensive mitigation scenario versus the traditional management scenario 

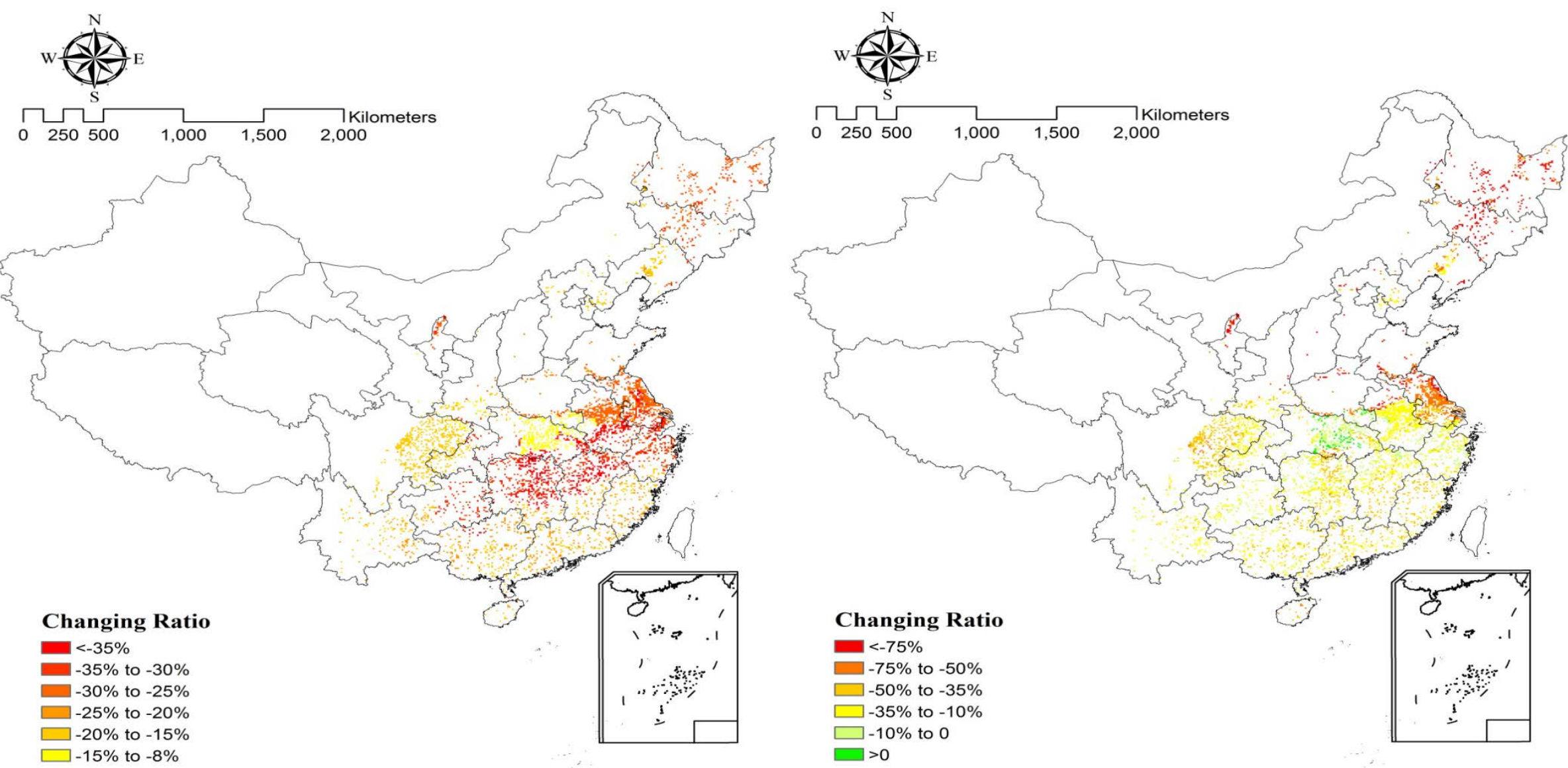

839 Figure 7. Changes in $\mathrm{CH}_{4}$ emission (left, denoted as Figure 7-a.) and $\mathrm{N}_{2} \mathrm{O}$ emission (right, Figure 7-b.) at the grid-cell level under the comprehensive mitigation scenario versus traditional management scenario 